\title{
Cross-country and intertemporal indexes of risk aversion
}

Received: 29th January, 2002

\section{Mark Kritzman*}

CFA is Managing Partner or Windham Capital Management Boston, a Senior Partner of State Street Associates, and the Research Director of the AIMR Research Foundation. Mr Kritzman holds a BS degree in economics from St John's University and an MBA with distinction from New York University.

\section{Kenneth Lowry}

CFA is a Vice President with Global Link, the e-commerce arm of State Street Corporation. Mr Lowry holds a BS in mathematics and computer science from Trinity College (Hartford) and an MBA from the Yale School of Management.

\section{Anne-Sophie Van Royen}

is Senior Quantitative Strategist for State Street Associates, LLC. She holds a PhD in Mathematical Economics from the Université de Paris-Sorbonne, France. She also holds an MA in Business Studies from the Ecole des Hautes Etudes Commerciales, France.

*WCMB, 5 Revere Street, Cambridge, MA 02138, USA Tel: +1 617576 7360; e-mail: mkritzman@wcmbllc.com

Abstract One of the most common and firmly held views of financial economics is that investors are averse to risk. Although a formal description of risk aversion was proposed by the celebrated mathematician, Daniel Bernoulli, as early as 1738, financial economists are still puzzled about many aspects of risk aversion, including the fact that the realised premium of equities over a risk free asset is too large to accord with 'normal' notions of risk aversion. This discrepancy is known as the equity risk premium puzzle. There is also vigorous debate as to the effect of horizon on the willingness of investors to bear risk. To help address these issues and other questions related to risk aversion, a methodology is introduced to infer risk aversion from global portfolio flows and holdings. Specifically, the authors derive a formula for risk aversion based on the assumption that investors maximise expected utility by allocating their portfolio between assets of differing risk. The authors use this formula to approximate the risk aversion of US investors towards specific countries. They demonstrate that risk aversion, as they approximate it, helps to predict bond and stock returns, as well as risk premiums one period forward.

Keywords: risk aversion; expected utility; portfolio flows; portfolio holdings; panel regression; risk premium

\section{Introduction}

One of the most common and firmly held views of financial economics is that investors are averse to risk. In fact, a formal description of risk aversion was proposed by the celebrated mathematician, Daniel Bernoulli, as early as 1738 (1954).

Bernoulli described the following game. Two participants, each of whom has 100 ducats, contribute 50 ducats as a stake in a game in which the chance of 
Table 1 Expected utility of participating in fair game

\begin{tabular}{llll}
\hline Pay-off & Utility of pay-off & $\begin{array}{l}\text { Probability of pay-off } \\
(\%)\end{array}$ & Probability-weighted pay-off \\
\hline 50 & 3.91 & 50 & 1.96 \\
150 & 5.01 & 50 & 2.51 \\
Expected utility & 4.46 & & \\
\hline
\end{tabular}

winning is determined by the toss of a coin. Each player, therefore, has an even chance of ending up with 50 ducats or 150 ducats. The expected value of this game is identical to the value of not playing, because each player starts out with 100 ducats. Bernoulli argued, however, that most people would choose not to play this game because the utility of not participating is higher than the utility of participating. Bernoulli assumed that utility is equal to the logarithm of wealth. Given this assumption, the utility of not participating equals $4.61[\ln (100)]$, whereas the utility of participating equals 4.46, as shown in Table 1.

Bernoulli's concept of utility implies that people prefer a certain prospect to an uncertain prospect of equal expected value, which is to say people are risk averse. Indeed, Bernoulli interpreted risk aversion as 'nature's admonition to avoid the dice' (Bernoulli, 1954: 29). Two centuries later, von Neumann and Morgenstern (1944) formalised the notion of expected utility, ${ }^{1}$ and other economists have since extended their insights. Friedman and Savage (1948), for example, hypothesised that individuals may be risk averse for certain levels of wealth and risk seeking for others.

Financial economists, however, are still puzzled about many aspects of risk aversion. They are puzzled by the fact that the realised premium of equities over a risk-free asset is too large to accord with 'normal' notions of risk aversion. This discrepancy is known as the equity risk premium puzzle. There is also vigorous debate as to the effect of horizon on the willingness of investors to bear risk. To help address these issues and other questions related to risk aversion, this paper introduces a methodology to infer risk aversion from global portfolio flows and holdings. This methodology is applied to estimate cross-country and intertemporal indexes of risk aversion, to facilitate empirical analysis of risk aversion.

In the second section, a formula is derived for risk aversion based on the assumption that investors maximise expected utility by allocating their portfolio between assets of differing risk. This formula is also modified to approximate the risk aversion of US investors towards specific countries. In the third section, the assumptions are presented and the data described. The results are presented in the fourth section. Specifically, the temporal variation of risk aversion implied by the changes in allocation of US investors to global stocks and bonds is shown. Also presented are the risk-aversion indexes of US investors towards specific countries. It is demonstrated that risk aversion, as it is approximated, helps to predict bond and stock returns, as well as risk premiums one period forward. The fifth section summarises.

\section{Derivation of risk aversion}

The initial assumption is that investors maximise expected utility as a function of allocation to assets of differing risk. 
Consider $n$ assets and a standard Markowitz (1952) utility function, defined as the expected return minus the product of risk aversion and variance:

$$
\begin{aligned}
E(U)= & W^{\prime} M-\lambda W^{\prime} \Omega W \\
= & \sum_{i=1}^{n} w_{i} \mu_{i}-\lambda\left(\sum_{i=1}^{n} w_{i}^{2} \sigma_{i}^{2}\right. \\
& \left.+2 \sum_{i=1}^{n} \sum_{j>i} w_{i} w_{j} \sigma_{i j}\right)
\end{aligned}
$$

where $W=\left(w_{i}, w_{2}, \ldots, w_{n}\right)^{\prime}$ is a set of asset weights, $M=\left(\mu_{i}, \mu_{2}, \ldots, \mu_{n}\right)^{\prime}$ is the vector of expected returns, $\lambda$ is the coefficient of risk aversion, and $\Omega$ is the covariance matrix of asset returns.

Portfolio optimisation is a process by which expected utility is maximised with respect to asset weights, under the constraint that the asset weights sum to one. The solution to (1) is found by taking the partial derivatives of the following expression:

$$
\begin{aligned}
l= & \sum_{i=1}^{n} w_{i} \mu_{i}-\lambda\left(\sum_{i=1}^{n} w_{i}^{2} \sigma_{i}^{2}\right. \\
& \left.+2 \sum_{i=1}^{n} \sum_{j>1} w_{i} w_{j} \sigma_{i j}\right) \kappa\left(1-\sum_{i=1}^{n} w_{i}\right)
\end{aligned}
$$

where $\kappa$ is the Lagrange multiplier.

A set of $n+1$ first-order conditions is obtained:

$$
\begin{aligned}
& \text { For } i=1 \ldots n: \frac{\partial E(U)}{\partial w_{i}} \\
& \quad=\mu_{i}-\lambda\left(2 w_{i} \sigma_{i}^{2}+2 \sum_{j \neq 1} w_{j} \sigma_{i j}\right)-\kappa=0 \\
& \text { and } \frac{\partial E(U)}{\partial \beta}=1-\sum_{i=1}^{n} w_{i}=0
\end{aligned}
$$

The optimal weights $W^{\star}$ that satisfy these conditions constitute the solution to the asset allocation problem. At the optimum, in which the expected utility is maximised for a given level of risk aversion, the derivatives of the expected utility with respect to the optimal weights are all equal to one another. Therefore, in order to extract the risk-aversion coefficient, the optimisation process is reverse engineered by setting any two of these equations equal to one another:

$$
\begin{gathered}
\mu_{i}-\lambda\left(2 w_{i}^{\star} \sigma_{i}^{2}+2 \sum_{j \neq i} w_{j}^{\star} \sigma_{i j}\right)=\mu_{j} \\
-\lambda\left(2 w_{j}^{\star} \sigma_{j}^{2}+2 \sum_{k \neq j} w_{k} \sigma_{k j}\right)
\end{gathered}
$$

which leads to:

$$
\begin{aligned}
\lambda= & \frac{\mu_{i}-\mu_{j}}{2 w_{i}^{\star} \sigma_{i}^{2}+2 \sum_{j \neq i} w_{j}^{\star} \sigma_{i j}-2 w_{j}^{\star} \sigma_{j}^{2}-2 \sum_{k \neq j} w_{k} \sigma_{k j}} \\
& \text { for any } i \neq j
\end{aligned}
$$

If the asset weights are optimal, the formula above represents the global risk-aversion coefficient. In practice, historical assets weights are used to differentiate the risk aversion of US investors towards individual countries. The subscripts $i$ and $j$ in Equation (4), for example, would correspond respectively to stocks and bonds in Japan. In effect, the following question is answered: Controlling for the effect of exposure to other assets, how does exposure to a particular country contribute towards risk aversion? To proceed, as indicated above set the partial derivatives of expected utility with respect to the stock and bond weights within each country equal to each other. The calculation of these country specific partial derivatives, however, incorporates the covariances of returns across all assets, not just stocks and bonds for that particular country.

For a portfolio that comprises stocks and bonds, the expected utility is written as:

$$
\begin{aligned}
E(U)= & \mu-\lambda \sigma^{2} \\
= & w_{\mathrm{S}} \mu_{\mathrm{S}}+w_{\mathrm{B}} \mu_{\mathrm{B}}-\lambda\left(w_{\mathrm{S}}^{2} \sigma_{\mathrm{S}}^{2}\right. \\
& \left.+w_{\mathrm{B}}^{2} \sigma_{B}^{2}+2 w_{\mathrm{S}} w_{\mathrm{B}} \sigma_{\mathrm{BS}}\right)
\end{aligned}
$$


where $\mu_{\mathrm{S}}$ is the expected return of stocks, $w_{\mathrm{S}}$ is the weighting of stocks, $\mu_{\mathrm{B}}$ is the expected return of bonds, $w_{\mathrm{B}}$ is the weighting of bonds, $\sigma_{\mathrm{S}}$ is the standard deviation of stocks, $\sigma_{\mathrm{B}}$ is the standard deviation of bonds, and $\sigma_{\mathrm{BS}}$ is the covariance of stocks and bonds.

Applying (4), it is found that

$$
\lambda=\frac{\mu_{\mathrm{S}}-\mu_{\mathrm{B}}}{2\left[w_{\mathrm{S}}^{\star} \sigma_{\mathrm{S}}^{2}-w_{\mathrm{B}} \sigma_{\mathrm{B}}^{2}+\left(w_{\mathrm{B}}^{\star}-w_{\mathrm{S}}^{\star}\right) \sigma_{\mathrm{BS}}\right]}
$$

Equation (6) shows that average risk aversion can be quantified for any group of investors who divide their portfolios between stocks and bonds as long as their expectations about returns and risk can be estimated and as long as their portfolios' exposure to stocks and bonds are known. ${ }^{2}$

\section{Assumptions and data}

To measure risk aversion, seven values need to be estimated for each country:

(1) expected return for stocks, (2) expected return for bonds, (3) standard deviation of stocks, (4) standard deviation of bonds, (5) correlation of stocks and bonds, (6) exposure to stocks, and (7) exposure to bonds. The countries for which data are available are Australia, Canada, France, Germany, Japan and the US.

Begin with the assumption that the expected return of each asset class is proportional to the beta of that asset class with respect to a global stock and bond portfolio. These are the returns that would occur if markets were integrated and in equilibrium. The global portfolio is represented as a $60 / 40$ blend of the MSCI World Stock Index and the Salomon World Global Bond Index. Five years of monthly returns of this global portfolio are used, along with the MSCI country stock returns to estimate each country's stock beta and the Salomon country bond returns to estimate each country's bond beta. All returns are measured in US dollars. The global riskless rate is the interest rate on the three-month US Treasury bill. Each country's expected stock return, therefore, equals:

$$
\mu_{\mathrm{s}}=r_{\mathrm{f}}+\beta_{\mathrm{s}}\left(\mu_{\mathrm{G}}-r_{\mathrm{f}}\right)
$$

where $r_{\mathrm{f}}$ is the expected global risk-free return, $\beta_{\mathrm{S}}$ is the stock beta with respect to global stock and bond portfolio, and $\mu_{\mathrm{G}}$ is the expected return of global portfolio (annualised arithmetic average of monthly returns over the previous five years).

Similarly, each country's expected bond return equals:

$$
\mu_{\mathrm{B}}=r_{\mathrm{f}}+\beta_{\mathrm{B}}\left(\mu_{\mathrm{G}}-r_{\mathrm{f}}\right)
$$

where $\beta_{\mathrm{B}}$ is the stock beta with respect to global stock and bond portfolio.

Annualised standard deviations and the correlation of stock and bond returns from monthly returns over the previous five years are also estimated.

The last pieces of information needed to estimate risk aversion are the stock and bond exposures in each country. To arrive at this information, monthly data from the US Treasury Department are used. The Treasury Department publishes the transactions of long-term securities between US investors and foreigners. ${ }^{3}$ This information is based on mandatory submissions from banks and other financial institutions that deal with foreign residents. Net flows are calculated as the difference between purchases and sales by US residents of foreign stocks and bonds.

From these flow data, portfolio holding indexes of stocks and bonds in each country are constructed, beginning with index levels published by the US Department of Commerce as of 31st 


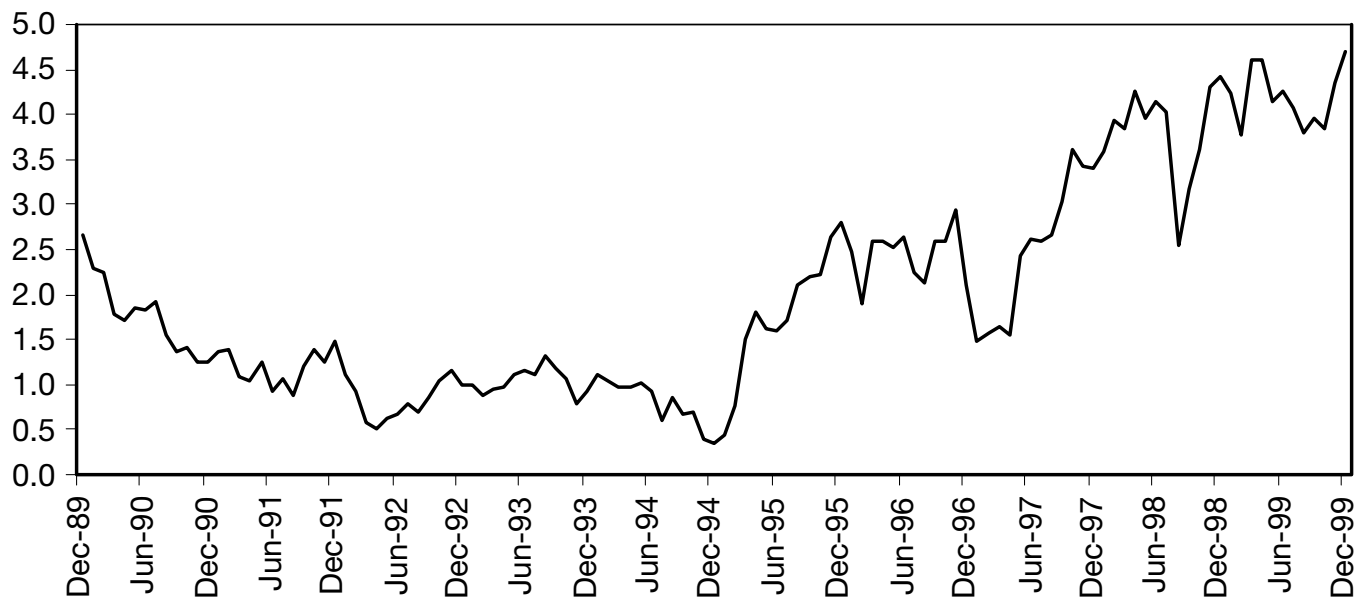

Figure 1 Global risk-aversion index

December, 1998. ${ }^{4}$ Holdings of foreign assets are estimated, assuming that flows occur at the middle of each month. The following expressions are for bonds and stocks in each country:

$$
H_{t-1}=\frac{H_{t}}{1+r_{t}}-\frac{F_{t}}{\left(1+r_{t}\right)^{1 / 2}}
$$

for holdings before November 1998

$$
H_{t}=\left(1+r_{t}\right) H_{t-1}+\left(1+r_{t}\right)^{1 / 2} F_{t}
$$

for holdings after January 1999

where $H_{t}$ are the holdings of foreign assets at time $t, F_{t}$ are net purchases of foreign assets between time $t-1$ and $t$, and $r_{t}$ is the interest rate between time $t-1$ and $t$.

For stocks, the relevant discount rate is the MSCI total returns index. The Salomon Government Bond index (7-10 years maturity) is used for the bond discount rate.

Stock and bond exposures are defined respectively as stock holdings divided by total holdings and bond holdings divided by total holdings. Now all of the information needed is available to estimate risk aversion.

\section{Results}

First, a global risk-aversion index beginning December 1989 is computed using Equation (6). Consider a portfolio including two assets, global stocks and global bonds. These composite assets are constructed using country stock and bond returns and the corresponding holdings (Figure 1).

The three vertical lines in Figure 1 divide the sample into four distinct risk-aversion regimes, corresponding to the global financial crises of the 1990s. The period up to December 1994 is characterized by a relatively steady decline in risk aversion. The European Monetary System crisis in 1992 produced a slight increase in the index. Perhaps if this sample included the UK or Italy, the increase would have been more pronounced. A second period starting in late 1994 coincides with the Mexican crisis. Risk aversion increased sharply beginning at the end of 1994, following the crash of the peso. It continued at a high level with a fair degree of volatility throughout 1995 and 1996, as investors remained sceptical about the bailout, and it eventually retreated when investors became convinced of its success. A third 


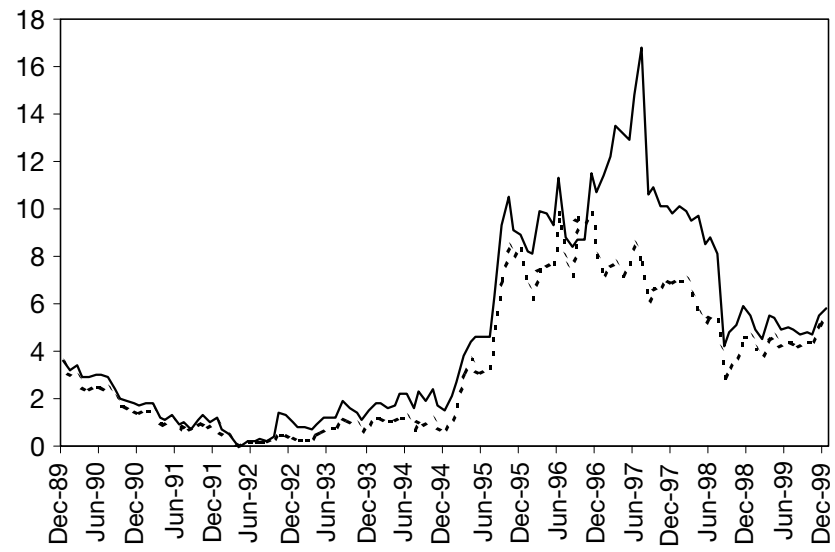

- Australia ....... Canada

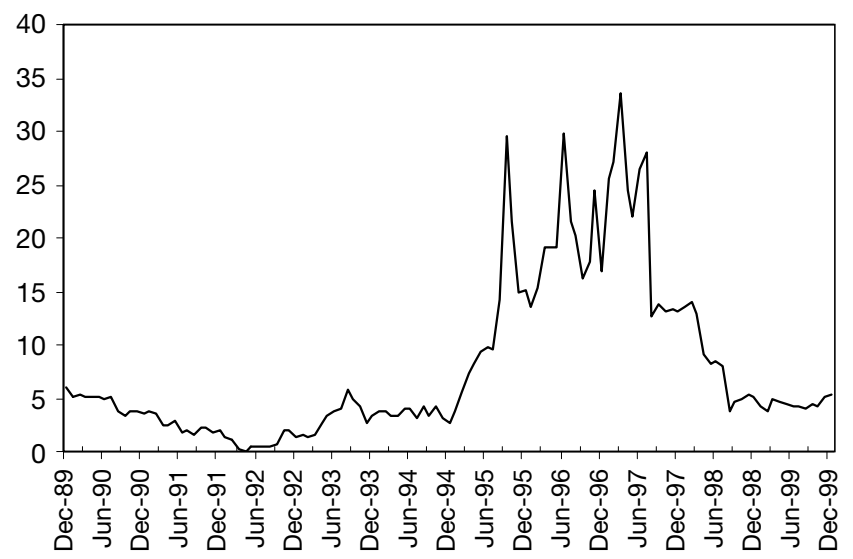

- Japan

Figure 2 Country risk-aversion indexes of US investors

period begins in April 1997, two months before the start of the Asian crisis. This period is characterised by a very sharp increase in global risk aversion. The fourth period coincides with the Russian crisis. The index collapsed by 47 per cent in August 1998. This may seem paradoxical, as it would be expected that risk aversion had increased. This apparent decline in risk aversion occurred, however, because the required stock premium did not rise sufficiently to compensate for the increased volatility of stock returns. ${ }^{5}$ In other words, investors at that time did not fully appreciate the
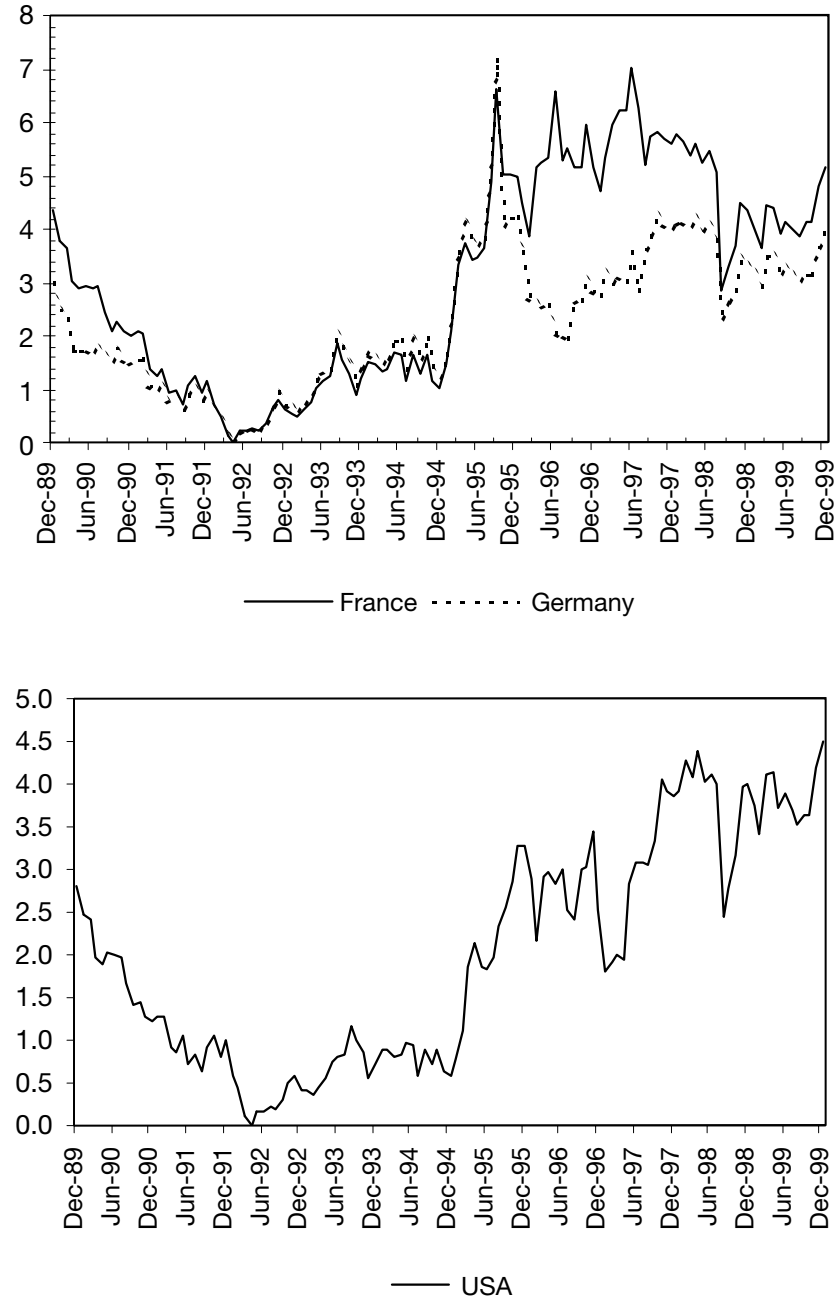

severity of the Russian default and its impact on financial institutions such as Long Term Capital Management. When the severity of the financial markets' problems was gradually disclosed, risk aversion rose concomitantly and remained near historic highs to the end of 1999.

Country-specific indexes are also calculated. The index for the US looks similar to the global index presented above, because the US market is such a large fraction of the total market. ${ }^{6}$ US investors have the lowest degree of risk aversion towards the US, which may 
Table 2 Panel regressions (non-overlapping periods)

\begin{tabular}{llll}
\hline & & $\begin{array}{l}\text { Frequency } \mathbf{6} \text { months } \\
\text { No. of regressions 20 }\end{array}$ & $\begin{array}{l}\text { Frequency 1 year } \\
\text { No. of regressions 10 }\end{array}$ \\
\hline \multirow{2}{*}{ Percentage of significant coefficients } & Risk premiums & 35 & 40 \\
& Stock returns & 45 & 50 \\
& Bond returns & 40 & 50 \\
\hline
\end{tabular}

reflect familiarity with their local markets, followed by Germany and France (see Figure 2). They are most averse to Japan.

Although country indexes are highly correlated with one another (the average correlation is 80 per cent), they reveal important country-specific and regional effects. The Canadian index increased 66 per cent between August and October 1995, before the referendum in Quebec, which occurred on 30th October. US investors became most risk averse to Australia in July 1997, at the beginning of the Asian crisis. Risk aversion of US investors towards France peaked at the end of September 1995, one month before the resignation of the Conservative government, and again in June 1997, when a Socialist cabinet was elected. $^{7}$

In addition to the official data described above, information on portfolio flows and holdings provided by State Street Bank and Trust Company was used. State Street Bank is one of the world's largest custodians, with over 40 per cent of the mutual fund industry under custody - and over \$6trillion in total. It records details of all transactions for the securities held in custody and is able to identify purchases and sales of both debt and equity. This daily data were made available to the authors from August 1994 and enable us to observe the flows of large institutional investors in foreign markets.

The State Street Bank data on portfolio flows confirm the results based on the US Treasury data. Four countries were present in both samples: Australia, Canada, Japan and the US. The correlations between each pair of country-specific risk-aversion indexes vary between 82 per cent and 96 per cent, reflecting the reliability of the US Treasury-based estimates.

\section{Risk aversion and returns}

It is now examined whether risk aversion helps to predict future returns. Because only 10 years of monthly data are available for risk aversion, all observations are pooled for the six countries, and a panel regression model is used in which the intercept is allowed to change for each country, but the slope coefficient associated with last month's change in risk aversion is identical across all six countries. This regression model is expressed as follows:

$$
r_{i, t}=\alpha_{i}+\beta \Delta a_{i, t-1}+\varepsilon_{i, t}
$$

where $r_{i, t}$ is the monthly return for country $i$ at time $t$,

$\Delta a_{t-1}=\log \left(a_{i, t-1}\right)-\log \left(a_{i, t-2}\right)$ is the rate of change in risk aversion for country $i$ between $t-2$ and $t-1$, and $\varepsilon_{i, t}$ is the error term distributed $N(0.1)$.

Regressions are conducted over non-overlapping windows of six months and one year with the following dependent variables: stock returns, bond returns and risk premiums, defined as the difference between the two (Table 2). The percentage of times that the 
Table 3 Panel regressions (overlapping periods)

\begin{tabular}{lccc}
\hline & Risk premiums & Stock returns & Bond returns \\
\hline All regressions & & & \\
Average $R^{2}$ & $6.42 \%$ & $4.76 \%$ & $4.59 \%$ \\
Average coefficient & -0.0004 & -0.0042 & -0.0038 \\
Standard deviation coefficient & 0.0479 & 0.0302 & 0.0248 \\
Percentage coefficient $>0$ & $22 \%$ & $24 \%$ & $38 \%$ \\
Regressions with significant coefficient & $77 \%$ & $53 \%$ & $45 \%$ \\
Percentage significant coefficient & $6.91 \%$ & $4.55 \%$ & $6.63 \%$ \\
Average $R^{2}$ & 0 & -0.0052 & -0.0086 \\
Average coefficient & & & \\
\hline
\end{tabular}

coefficient associated with risk aversion is significant at a 10 per cent confidence level is reported.

Risk aversion appears to predict bond and stock returns better than it predicts risk premiums. The percentage of regressions in which risk aversion is significant is always substantially greater than 10 per cent, the percentage that would be expected if the relationship between risk aversion and returns were random, given the choice of confidence level.

Panel regressions are now conducted using Equation (10) over a two-year rolling window and compute one-month ahead return forecasts. The results are summarised in Table 3.

These results suggest that changes in risk aversion have some ability to forecast returns. The average $R^{2}$ is between 4 per cent and 6 per cent. Slope coefficients are small but significant in more than 45 per cent of the regressions. The change in risk aversion is most often significant in the case of risk premiums, followed by stock returns.

We propose two hypotheses about the direction of the relation between risk aversion and returns:

\section{Delayed reaction to changes in} risk aversion: In order to compensate investors for higher risk aversion, stock returns must increase. As investors shift towards stocks, bond returns decrease, which raises the risk premium. The expected coefficients are positive for both stock returns and risk premiums and negative for bond returns.

2 Immediate reaction to changes in risk aversion: Investors are immediately compensated for higher risk aversion. The following month, stock returns decrease and bond returns increase, which results in a decline in risk premiums.

The results are inconclusive about the direction of the relation based on the entire set of regressions, ${ }^{8}$ and even the subset of regressions with significant slope coefficients. The relationship between risk aversion and returns, however, seems to have changed in August 1998. Risk aversion has subsequently become more important with respect to returns.

Moreover, the results since August 1998 tend to support the first hypothesis of delayed reaction, with a positive coefficient for stock returns and risk premiums, and a negative coefficient for bond returns. The evolution of the coefficient associated with changes in risk aversion is plotted in Figure 3.

\section{Summary}

- Financial economists are puzzled about the nature of risk aversion because realised risk premiums seem 


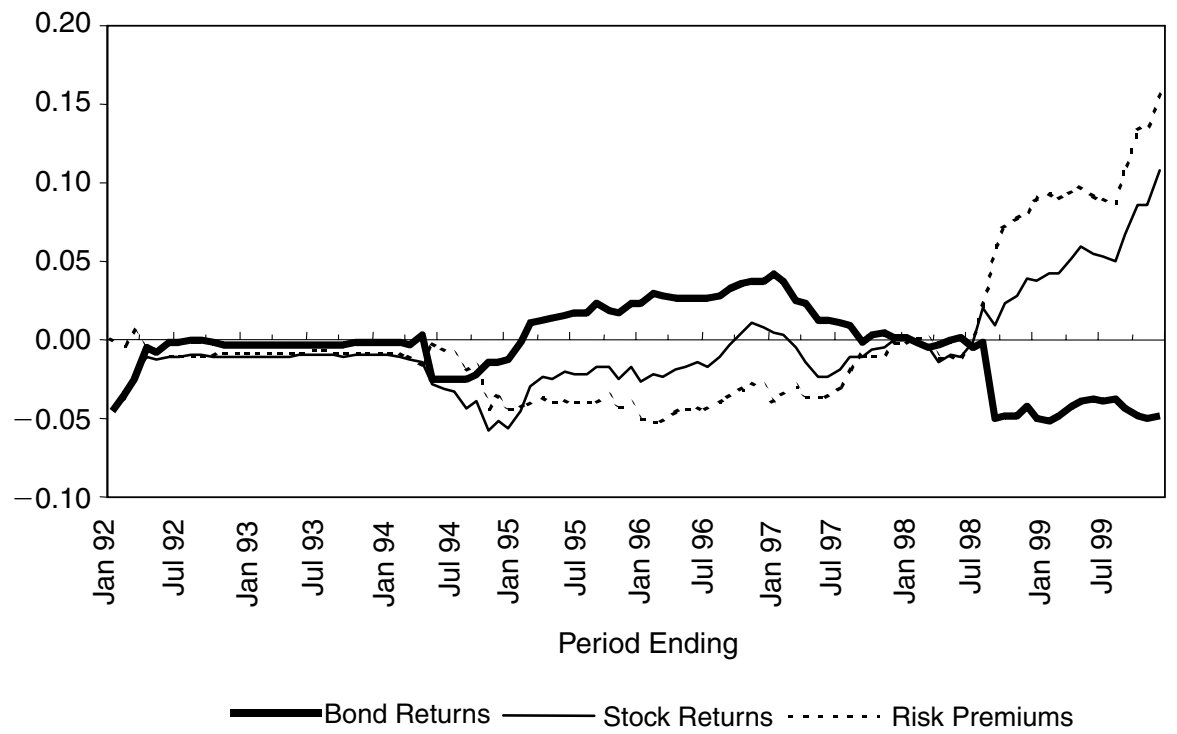

Figure 3 Regression coefficients

too large to accord with common views of risk aversion and because the relation between risk aversion and horizon seems to contradict utility theory. It may, therefore, be beneficial to measure differences in risk aversion across countries and through time in order to facilitate empirical analysis of risk aversion.

- Global and country specific risk-aversion indexes are constructed from portfolio holdings data by reverse engineering the mean-variance optimisation process.

- The results show a clear increase in global risk aversion around the Mexican and Asian crises, and a surprising drop in risk aversion at the time of the Russian crisis. It is believed that this latter result is because subsequent returns did not rise sufficiently to compensate for the rise in volatility during the Russian crisis.

- The results are also consistent with expectations at the country-specific level. For example, risk aversion towards Canada rose substantially in advance of the Canadian referendum on the independence of Quebec, US investors became more risk averse towards Australia during the Asian crisis, and they became more risk averse towards France when the Conservative government was defeated and at the time a Socialist cabinet was elected.

- It was also found that cross-country differences in risk aversion help to explain differences in realised returns one month forward. Although the coefficients are significant substantially more often than would occur randomly, the signs are not consistent with a uniform hypothesis of the relation between risk aversion and return. This inconsistency may be attributed to omitted variables.

\section{Notes}

1 If an agent has preferences defined over lotteries, then there is a utility function that assigns a utility to every lottery that represents these preferences.

2 This approximation assumes implicitly that the component assets within stocks and within bonds are either fixed or optimally balanced. 
3 Available online from the Treasury website at http://www.treas.gov.tic/ticsecd.htm

4 Published in 'The International Investment Position of the United States at Year End 1998', Tables D and E, July 1999, Bureau of Economic Analysis. The data were recently revised to reflect preliminary results from the Treasury Department's and Federal Reserve System's Benchmark Survey of US

Ownership of Foreign Long-Term Securities (as of 31st December, 1997).

5 The stock premium appears in the numerator of the risk-aversion formula, whereas the volatility terms appear in the denominator; thus the stock premium must rise sufficiently to offset an increase in volatility in order for risk aversion to rise.

6 US stocks and bonds represent on average 95 per cent of the holdings.

7 The peaks in the Japanese index are due to jumps in the expected stock premium.
8 The mean is slightly negative, but the standard deviation is large.

\section{References}

Arrow, K. J. (1965) Aspects of the Theory of Risk-Bearing, Yrjö Hahnsson Foundation, Helsinki.

Bernoulli, D. (1954) 'Exposition of a New Theory on the Measurement of Risk', Econometrica, January (translation from 1738 version).

Friedman, M. and Savage, L. P. (1948) 'The Utility Analysis of Choices involving Risk', Journal of Political Economy, 56, 279-304.

Markowitz, H. (1952) 'Portfolio Selection', Journal of Finance, March.

Von Neumann, J. and Morgenstern, O. (1944) Theory of Games and Economic Behavior, 1953 edn, Princeton University Press, Princeton, NJ 